\title{
An Engaging, Yet Failed Flip
}

\author{
Kevin S. Krahenbuhl, EdD \\ Assistant Professor, College of Education \\ Middle Tennessee State University
}

The flipped classroom is growing significantly as a model of learning in higher education. However, there are ample problems with the research on flipped classrooms, including where success is often defined by student perceptions and a lack of consistent, empirical research supporting improved academic learning. This quasi-experimental study describes a semesterlong comparison of two of the same courses taught by the same instructor utilizing a primarily didactic lecture approach and a flipped classroom approach. The experiment found results in which students in the didactic lecture class had significantly higher end-of-course scores than those in the flipped classroom; however, with regards to a document-based analytic essay question there was no statistically significant difference.

Institutions of higher education are facing considerable challenges in the twenty-first century. While there are many challenges, perhaps two of the most important are the diverging demands of increasing access and increasing outputs in terms of graduates. On one hand, institutions are pushed to enroll more and more students. Of significance for discussion here are the increase of these new students who are, statistically speaking, among the least likely to succeed in college (Tinto \& Pusser, 2006). On the other hand, the institutions are increasingly being evaluated by the public in terms of their retention and graduation rates (Eaker \& Sells, 2015). Correspondingly, there is growing interest and advocacy for change in the classroom since that is at the core of where issues regarding student success must reside. And at the core of the pushes for change are the many voices seeking to see increased emphasis on technology-integration in the classroom as a means to promote student development for the 21st century.

In particular, many are now seeking to integrate technology more frequently and to use it specifically as a means for improving learning outcomes of students. The pervasive force of technology is undoubtedly a driving force in our age of information, communication, and globalization. And through technology, we are seeing major shifts occurring within the walls of academia.

\section{Literature Review}

One of the most prominent of these changes is the increase in use of the flipped classroom. Since its popularization by Bergmann and Sams (2009) there has been an increasing optimism towards flipping one's class. The flipped classroom alters the traditional model for instructional allocation of time so that what had been traditionally done during class time (lectures) are completed using technology as homework and the notion is to do so to create much more engaging classroom activities, discussions, and opportunities for looking deeper at course content. Some studies have found evidence suggesting that flipping the classroom can improve student learning (McLaughlin et al., 2014; Stone, 2012). However, such empirical 
studies are few and far between when the emphasis of the research is on gains in student knowledge as measured in empirical means. So, while the flipped model of instruction is gaining popularity in both $\mathrm{K}-12$ and higher education settings, "there is very little scientifically based, empirical research to substantiate the effectiveness of this instructional model" (Fraga \& Harmon, 2015, p. 19).

And unfortunately, in many cases, the evidence shared regarding the 'success' of a flip is tainted from an inadequate definition of success. Illustrations of this include simply ascribing success as measured by student feedback on their perceptions as opposed to comparing learning gains against a reasonable control group (Abdulrahman, 2015; Dove, 2013; Gaughan, 2014). Another example of this stems from Toto and Nguyen (2009) in which the researchers used the learning styles of students along with their perceptions to determine which were perceived as being most impactful for learners. This particular study faces several problems. First off, the empirical research on "learning styles" indicates that they simply do not exist (De Bruyckere, Kirschner, \& Hulshof, 2015; Pashler, McDaniel, Rohrerr, \& Bjork, 2009; Willingham, 2009;). Secondly, there is also empirical evidence suggesting that students may know what they prefer, but that their preference often does not correlate to improved learning. Rather, student preference is often misleading or outright incorrect with regards to their actual learning because they generally prefer what is easier and not what improves learning (Kirschner, \& van Merrienboer, 2013). This is an important reality for researchers to consider because use of student preferences and perceptions are becoming increasingly utilized as a metric for improving learning environments but as noted, are more often than not, incorrect.

Additionally, there is frequently a significant pedagogical antipathy held by many towards the lecture (Sipress \& Voelker, 2008; Solomon, 2004) that is evident within the narratives of many researchers. Such obvious disdain for the 'comparison group' at least suggests that there is a real potential for those implementing the methods to fail to adequately present each in the best of all circumstances. This dovetails with a growing sense of concern regarding the real learning that takes place on college campuses (Arum \& Roska, 2011). Ultimately, then, the problem that exists is that success is defined in a multitude of ways, many of which do not keep student learning at its core, and many use their definition of success and subsequent studies to draw conclusions that simply are not justified.

\section{Context and Purpose}

Thus, as an educator and pedagogue who values the lecture, loves technology and seeks to build in lots of discussion, I felt that exploring the flipped classroom would be of particular benefit in two ways. First, this study would be justifiably implemented by an instructor who acknowledges his own use and support for both the lecture and the integration of technology. As an avid user of technology, I particularly value its potential for enhancing assessment practices in the classroom (Krahenbuhl, 2016) and integrate it into instruction frequently in that regard. So, in completing a small-scale investigation as one who values didactic lecture, albeit desires more discussion and activity, I felt equipped to give a fair shake to the traditional method as a basis of reasonable comparison. Additionally, in 2014, the faculty at our small, rural 
college all were provided with Bergmann and Sams' (2012) Flip your classroom: Reach every student in every class every day. A group of six faculty members read and met biweekly to discuss their book and consider its potential for application in our courses. The reading and discussion of that book led to several of us trying out the flipped model in our courses in small scales, including flipping particular units to design, revise, and pilot videos of lectures for online viewing, and to follow up discussions reflecting on perceived impacts of our efforts. Ultimately, this quasi-experimental study describes the findings of a full-scale implementation of the flipped model as it was implemented and investigated in an American Indian history course. The model of the flipped class was focused on increasing in-depth discussions students could have in our face-to-face classes with facilitation of those discussions by the instructor ${ }^{1}$. In order to provide a direction of investigation and to add to the growing body of literature on flipped classrooms, the following hypotheses were developed to be tested: With regards to students' performance on an end-of-course selected response exam:

$\mathrm{H}_{0}: \mu$ FlippedMC $=\mu$ LectureMC

$\mathrm{H}_{1}: \mu$ FlippedMC $\neq \mu$ LectureMC

With regards to students' performance on an end-of-course document-based question:

HoA: $\mu$ FlippedDBQ $=\mu$ LectureDBQ

H1A: $\mu$ FlippedDBQ $\neq \mu$ LectureDBQ

The null hypotheses $\left(\mathrm{H}_{0}\right.$ and $\left.\mathrm{H}_{0 \mathrm{~A}}\right)$ each suggest that there will be no difference between mean performance of students in the flipped classroom and those in the lecture-based classroom. The alternative hypotheses $\left(\mathrm{H}_{1}\right.$ and $\left.\mathrm{H}_{1 \mathrm{~A}}\right)$ are both left as twotailed outcomes such that a statistically significant result would be found if the flipped classroom significantly outperformed the lecture-based classroom on either summative assessment or if the lecture-based classroom statistically outperformed the flipped classroom on either summative assessment. Furthermore, the hypotheses were deliberately designed to consider two forms of summative assessments - one more traditional: a selected-response end of course exam, and one more focused on application of learning: an end-of-course document-based essay question.

\section{Method}

This study employed a quasi-experimental design in which two sections of a history course for educators were taught in subsequent semesters, one as a primarily lecture-based course $(n=18)$, and the other as a flipped course $(n=20)$. The same

\footnotetext{
${ }^{1}$ Within the methodology section, you will find a specific elaboration on how the flipped class differed from the traditional class. But, hopefully offering this model gives the reader a general sense of the model used since the flipped class is not necessarily a oneway only method. A short online article includes a nice summary of this approach and its alignment to history classes: https://www.panopto.com/blog/7-unique-flippedclassroom-models-right/.
} 
instructor ${ }^{2}$ taught both sections, and both courses had the same number of class meetings and total number of face-to-face hours. The lecture-based course was taught in the fall of 2015 and the flipped class was taught in the spring of 2016 ${ }^{3}$. Each section met on Tuesday and Wednesday from 11-12:15 during its respective academic semester. On the first day of each semester, students were informed that their class was designed to specifically be part of an IRB-approved investigation on instructional delivery modality. The students were informed that anonymized and aggregated data would be used to compare modalities for student learning and provided informed consent forms. All students agreed to participate and if any would have refused it would have had no impact on their enrollment or participation in the course, merely their data would have been exempted.

The major assessments used were identical and the same content and objectives were used in a backwards design model for building each course. Students enrolled in the course using typical registration methods and had no knowledge of different instructional formats in either section. On the first day of each section, students were informed that the class was using its particular method of instruction as part of a study and informed content was obtained; however, details of the intervention and its comparison were not specified.

Within both courses, there were of course variations in use of class time but each attempted to follow a template for consistency of delivery. First, the same Power Point presentations were utilized in both settings. In the lecture-based course, they were used during the didactic lecture with the class and in the flipped class, the Power Points were integrated into and/or utilized in design of the video lectures. However, the flipped class sought to create concise and focused videos of less than ten minutes in length in accord with recommendations (EDUCAUSE Learning Initiative, 2012). In a few instances, two or three shorter videos (approximately 5 minutes each) were used when conceptually appropriate. Lecture videos were created with several different tools including Adobe Voice and Camtasia as primary means. The video lectures were developed during the fall of 2015 during the week in which they were being delivered to the lecture-based sections. It was thought that this would benefit the instructor in ensuring topical consistency and simply helping focus on key concepts in the fall course itself. In all instances, the flipped class was provided the full Power Point presentations as a supplement to download and the face-to-face class was provided the full Power Point as well as a supplement to download on the course management system's course site. This was another point of commonality. Both courses had an electronic platform through Desire 2 Learn (D2L) that included weekly agendas, materials for download, discussion forums, and quizzes.

There were two primary differences in each face-to-face session, although it should be noted that as with any course, there were many divergences from this template. The first primary difference for each section included either an instructor-

2 The instructor is the author and thus, the reader should be clear on that and its potential for bias. However, I hope to have conveyed well that I am a strong supporter for both lectures and the leveraging of technology to enhance learning as evidenced by past publications in addition to my own assertions as such. 
driven class review and discussion from the readings (lecture-based class) or a studentled, instructor-facilitated, small group activity reviewing material from the web-based lecture and associated readings (flipped class). The second primary difference for each section was the inclusion of a didactic lecture (lecture-based class) or an in-depth time of class discussions and/or activities (flipped class). The flipped class sought to place a high emphasis on integration of discussions so discussion questions were frequent focal points for class time - sometimes generated by the instructor, sometimes by students. However, other methods were employed as deemed conceptually appropriate, including the use of Jigsaw activities (Aronson, Blaney, Stephen, Sikes, \& Snapp, 1978), exploration of comparative interpretations of historical events/people/ideas, primary source analysis, and video clips with extended discussion. In the lecture-based class, each of these were also employed but generally at a reduced scale as a result of less face-to-face class time. When possible, both sections utilized the same extension and/or reinforcement activities; however, based on formative data obtained from each class, adjustments were made as deemed necessary to maximize the productivity of each class.

The general templates for face-to-face time are outlined in Table 1 below.

Table 1

Class Flow Template of Typical Face-to-Face Meeting

\begin{tabular}{lll}
\hline Time & Lecture-Based Class & Flipped Class \\
\hline 11:00-11:05 & Welcome, Day Overview, \& Review & Welcome, Day Overview, \& Review \\
11:05-11:15 & $\begin{array}{l}\text { Extended Review and Q\&A from } \\
\text { Readings }\end{array}$ & Sub-Groups Opening Activity \\
& Lecture & Class Discussion \\
$11: 15-11: 45$ & Extension and/or Reinforcement & Extension and/or Reinforcement \\
$11: 45-12: 00$ & Activity & Activity \\
& Allocated as appropriate & Allocated as appropriate \\
12:00-12:10 & Closure, Review, \& To Do & Closure, Review, \& To Do \\
& Discussion & Discussion \\
\hline
\end{tabular}

Throughout the semester, the models were employed exclusively. It should be noted that when one student requested more lecture in the flipped classroom, the request was denied reminding her that the material was available online and that the alternative strategies employed during class time were included by design to improve learning outcomes. In terms of data collected to evaluate student performance, three primary assessments were utilized. At the beginning of each semester, all students completed a selected-response pre-assessment that consisted of twenty items. Each of the items was matched with an end-of-course selected response assessment given at the end of the semester that had a total of forty items. In addition to this, the end-ofcourse evaluation also included a document-based essay question evaluated using a nine-point rubric. All students were given a list of four possible topics for the document-based question two weeks prior to the administering of that assessment. An 
independent samples $t$-test was run to compare means of both groups on their end-ofcourse assessments (including both selected-response exam and document-based question). The pre-tests were explored descriptively to confirm that there were insignificant differences in each class regarding prior knowledge.

Although this investigation is primarily a quantitative study, some ex post facto qualitative data were collected from selected students to help make meaning of the findings. This took place solely at the end of each course in which several students were randomly selected and asked to participate in a focus group discussion on the section regarding their experiences. Four students were drawn from each section and all eight agreed to participate. The focus group sessions were transcribed, coded, and several specific quotes are drawn from them to provide some personal accounts to the quantitative results and following discussion, but the themes from within them are not woven into the findings because they were constructed as an after-the-fact inclusion.

\section{Results}

Table 2 outlines a summary of the descriptive data collected regarding both classes. Levene's Test for Equality of Variances reported significance values of .427 $\left(\mathrm{H}_{0}\right)$ and $.523\left(\mathrm{H}_{\circ \mathrm{A}}\right)$ respectively suggesting that equal variances could be assumed. This is an important assumption for a $t$-test so when interpreting results from SPSS the data that are reported herein are drawn from the test assuming equality of variances. So, the $t$-test for equality of means reported $t$-values of $2.626\left(\mathrm{H}_{0}\right)$ and $1.752\left(\mathrm{H}_{\mathrm{oA}}\right)$. From these $t$-values, there is a statistically significant difference $(p=.013)$ in the mean performance of students on a selected-response assessment based on participation in a lecture class as opposed to a flipped class, $t(36), 2.63, p=.013$. Students in the flipped classroom $(M=62.39)$ performed worse than those in the lecture-based classroom $(M=$ 72.64) on the end-of-course selected response assessment. Given that the means reflect the overall percentage score out of a maximum of one-hundred, the lecture-based classroom scored a full letter grade higher on this selected-response assessment. The effect size was calculated using Cohen's $d$ to be .86 indicating a large effect. As such, we have reason to reject the first null hypothesis, $\mathrm{H}_{0}$. However, there was no statistically significant difference with regards to student performance on a documentbased analytic essay question, $t(36), 1.75, \mathrm{p}=.088$. Consequently, we fail to reject $\mathrm{H}_{0 \mathrm{~A}}$. On the document-based question, while the lecture-based class $(M=4.94)$ outperformed the flipped class $(M=3.95)$, the statistical analysis was not sufficient to proclaim any significant difference between the groups.

Table 2

\begin{tabular}{lccccccc}
\multicolumn{2}{l}{ Descriptive Statistics } \\
\hline Group & $n$ & $\begin{array}{c}\text { Pre-Test } \\
\text { Mean }\end{array}$ & $\begin{array}{c}\text { Pre-Test } \\
\text { SD }\end{array}$ & $\begin{array}{c}\text { Post-Test } \\
\text { Mean }\end{array}$ & $\begin{array}{c}\text { Post-Test } \\
\text { SD }\end{array}$ & $\begin{array}{c}\text { DBQ } \\
\text { Mean }\end{array}$ & $\begin{array}{c}\text { DBQ } \\
\text { SD }\end{array}$ \\
\hline $\begin{array}{l}\text { Lecture- } \\
\text { Based }\end{array}$ & 18 & 26.39 & 8.05 & 72.64 & 11.13 & 4.94 & 1.83 \\
$\begin{array}{l}\text { Class } \\
\text { Flipped }\end{array}$ & 20 & 25.25 & 7.48 & 62.39 & 12.75 & 3.95 & 1.67 \\
Class & & & & & & & \\
\hline
\end{tabular}




\section{Discussion}

\section{Practical Implications}

In both cases the students in the lecture-based class outperformed those in the flipped class; however, only with regard to the performance on a selected-response assessment did a statistically significant difference emerge. It is interesting that the document-based analytic essay question did not also ...an effective lecture is receive statistically significant findings. One might still an effective method wonder if there is some parallel between forms of to consider... assessments and alternative instructional methods that may serve as a confounding variable. Considering that there were no important differences among the groups from pre-test means nor variances in performance it lends support to the notion that an effective lecture-based class can outperform a flipped class. There are, of course, some obvious limitations with this study. First off, the sample was not randomly chosen nor did it include a large number of participants. As such, the study is not easily generalizable to larger student populations. Furthermore, this was the first full-scale flip of a class for the researcher while he had years of experience in a lecture-based class. While the collegial discussion of Bergmann and Sams (2009) and small-scale applications and reflections hopefully helped reduce any failure to implementing the flipped model effectively, this is still something important to consider with respect to these findings. Considering these limitations, however, the disparity between groups and the large effect size suggest that an effective lecture is still an effective method to consider and does echo some of the concerns regarding the lack of empirical research into the flipped classroom.

Although the results of this study showed lower performances of students in the flipped classroom as opposed to the traditional, lecture-based classroom, there were several points to hone in on in reflection. First off, since students have a varied completion rate of all readings in normal undergraduate education, adding a video even a short one as the ones used here - on top of readings does not necessarily make discussion or collaborative work any better. In fact, many students may choose to watch the video exclusively and ignore - or at most skim - the readings. This was something echoed by the flipped class focus group. One student captured this sentiment when he stated: "You know, when the professor gives me a video and the reading is on the same thing, it's like, why spend the time reading the text when the video covers it better and quicker?"4 His rhetorical question captures a common challenge for the millennial and younger generations who seem to be in a constant effort to find immediate gratification so a short video trumps an extended read in their

\footnotetext{
${ }^{4}$ Of course, lectures should not be mere restatements of the reading and certainly were not designed to be so in this course, however, the parallel topics may have led to this perception among students. Perhaps, in redoing this study I might look carefully at lecture titles to be sure the students could not, on face-value alone, perceive them as being just another exploration of the same thing.
} 
mind. Considering this, were I to implement the flipped classroom again I would redesign the sub-groups opening activities such that they addressed material from the video and the text, specifically. While this would not guarantee increased productivity in discussion, it certainly would make an environment conducive to that.

Second, should many professors shift to more flipped classroom models and yet wish to hold onto the core readings, it seems we are merely shifting the burden of in-class work versus out-of-class work in a way that students are not normed for. This is not to say that it ought not to happen but surely we must be aware that students in five flipped classes in a semester who all maintain the reading deemed appropriate simply have five ${ }^{5}$ additional videos required to view per session. Bergmann and Sams (2012) have some suggestions on dealing with this issue in Chapter 8 of their book but it feels geared more towards K-12. And when all is said and done, extra work sounds good to me - but it is important to think beyond the scope of one's own classroom. The magnitude of multiple professors making a switch in a similar timeframe could pose an overload problem for students. This is another of those patterns of reaction I received in the flipped class focus group as another professor flipped his class the same time and at least six students were co-enrolled in my and his courses. These students both felt that the videos and the reading were too burdensome. I disagree but take their comments as valuable nonetheless and worthy of inclusion in this discussion for practical implications.

Third, there are a group of students who feel that when they pay to be in a college classroom, they are partly paying for the expertise of their instructor. In a flipped classroom, the instructor's role is not patently obvious and thus, it may be useful to underscore how your expertise has contributed to the design of the course as well as within the context of in-class activities. Another quote perfectly illustrated this challenge when one focus group member said, "I don't really care what my peers have to say about history. They know as little as I do. I took the class to learn from you, not them." As noted by Strayer (2012), there is a disequilibrium or unsettledness that students face in flipped classrooms and they "need support structures built into the course" (p. 192) to monitor learning and can help students see the expert role the instructor is playing in such an environment.

In identifying these three focal points for discussion, I wish to reiterate that the primary means in which I developed them was based off interactions with the focus groups and my own perceptions based on informal interactions throughout the semester. So for those who wish to employ a flipped classroom in the future, I suggest making it clear in advance your policy on videos and reading and setting a norm for that early on for the high standards you seek to set. Second, consider the context and culture of those whom you serve. If your students are not familiar with such a model, consider beginning small - both for your own sake and to help foster such a transition. And third, be sure to make it explicit how you, as the expert in the room, are contributing to the student's learning when they ask. Robyn Jackson (2010) outlined several principles master teachers embody and among these include knowing where

\footnotetext{
${ }^{5}$ Or more, of course they should not be excessively long, but nonetheless, it is worthy of consideration.
} 
the students are going, supporting them along the way, using feedback to help students grow, and never working harder than their students. All of these principles are clearly aligned with a flipped classroom but aren't quite as visible as a teacher who does the heavy lifting for a class. As such, this might be a good place to deliberately point out when these things are occurring and how they are helping students learn in the context of a flipped classroom.

\section{Implications for Research}

The flipped classroom has certainly shown potential to transform the classroom, to make active learning more prominent, and to "promote more teacher/student interactions" (Fraga \& Harmon, 2015, p. 19). However, given the lack of strong empirical research in support of its positive impact on student learning and the findings of this quasi-experimental investigation there are reasons to be judicious about jumping into this model. In terms of implications from this investigation, two stand out with respect to future research. First, the theoretical frameworks employed by researchers in flipped classrooms must clearly define success in a way that includes a specific focus on student learning. ${ }^{6}$ As noted by Kirschner and van Merrienboer (2013), "students are really not the best managers of their own learning with respect to... choosing the best way in which ...make it explicit how you, as the expert in the room, are contributing to the student's learning when they ask.

to study and learn" (p. 178). So, perhaps less emphasis ought to be placed on student's preferred way of learning as a means for defining success. Second, the findings of this small-scale study do reinforce some of the concerns held by researchers regarding the lack of empirical evidence for the flipped classroom. As such, it seems crucial that future research employ larger-scale and randomized experiments exploring the flipped classroom and various other models as well.

\section{Conclusion}

This experiment found that the flipped classroom was less effective than the didactic lecture method in this particular case. As such, it adds to the growing body of research using empirical methods to explore this model of instruction. Although the experiment had various limitations of consideration, the effect size, parallels to other research (Strayer, 2012), and that "there [remain] few research-based investigations that provide evidence about flipped classrooms" (Fraga \& Harmon, 2015, p. 19), it

\footnotetext{
${ }^{6}$ Success in and of itself is something there is much disagreement about what qualifies for. But, the claim here is that success of any instructional model should only be considered as it relates to "student learning". If student learning and performance are not considered, it seems wholly inadequate to justify a model for use when the purpose of any instructional model is to cultivate an environment that promotes student learning.
} 
suggests there is need for continued research before proclaiming that either particular instructional model is the way of the future.

Ultimately, this failed flip may underscore what others have already shared there is a significant need for randomized experiments (Bishop \& Verleger, 2013), as opposed to quasi-experiments, in order to come to any meaningful conclusions of the real impact of this methodology. While there is ample evidence that many students prefer more activity in the classroom, there are still those who wish to have the expert direct use of class time.

\section{References}

Abdulrahman, M. A. (2015). From passive to active: The impact of the flipped classroom through social learning platforms on higher education students' creative thinking. British Journal of Educational Technology, 46, 1133-1148.

Retrieved from http://onlinelibrary.wiley.com/journal/10. 1111/(ISSN)1467-8535

Aronson, E., Blaney, N., Stephen, C., Sikes, J., \& Snapp, M. (1978). The jigsaw classroom. Beverly Hills, CA: Sage.

Arum, R., \& Roska, J. (2011). Academically adrift: Limited learning on college campuses. Chicago, IL: University of Chicago Press.

Bergmann, J., \& Sams, A. (2009). Remixing chemistry class: Two Colorado teachers make vodcasts of their lectures to free up class time for hands-on activities. Learning $\mathcal{E}$ Leading with Technology, 36(4), 22-27. Retrieved from http://mtsu.worldcat.org/title/learningand-leading-with-technology-the-istejournal-of-educational-technologypractice-and-policy/oclc/32411727

Bergmann, J., \& Sams, A. (2012). Flip your classroom: Reach every student in every class every day. Alexandria, VA: ASCD.
Bishop, J. L., \& Verleger, M. A. (2013, June). The flipped classroom: A survey of the research. In ASEE National Conference Proceedings. Paper presented at the American Society of Engineering Education (ASEE) Annual Conference, Atlanta, GA. Retrieved from https://www.asee.org/search/proceeding $\mathrm{s}$

DeBruyckere, P., Kirschner, P. A., \& Hulshof, C. D. (2015). Urban myths about learning and education. San Diego, CA: Elsevier.

Dove, A. (2013). Students' perceptions of learning in a flipped statistics class. Paper presented at the Society for Information Technology \& Teacher Education International Conference, 2013, New Orleans, LA. Retrieved from: http://www.editlib.org/p/48133

Eaker, R., \& Sells, D. (2015). A new way: Introducing higher education to Professional Learning Communities at Work ${ }^{\mathrm{TM}}$. Bloomington, IN: Solution Tree Press.

EDUCAUSE Learning Initiative. (2012). 7 things you should know about... Flipped classrooms. Retrieved from https://net.educause.edu/ir/library/pdf/el i7081.pdf 
Fraga, L. M., \& Harmon, J. (2015). The flipped classroom model of learning in higher education: An investigation of preservice teachers' perspectives and achievement. Journal of Digital Learning in Teacher Education, 31(1), 18-27. doi: $10.1080 / 21532974.2014 .967420$

Gaughan, J. E. (2014). The flipped classroom in world history. The History Teacher, 47, 221-244. Retrieved from http://www.jstor.org/journal/historyteach er

Jackson, R. R. (2010). Never work harder than your students $\mathcal{E}$ other principles of great teaching. Alexandria, VA: ASCD.

Kirschner, P. A., \& van Merrienboer, J. J. G. (2013). Do learners really know best? Urban legends in education. Educational Psychologist, 48(3), 169-183. doi: 10.1080/00461520.2013.804395

Krahenbuhl, K. S. (2016, March). Enhancing assessment practices in history education with technology. Society for Information Technology \& Teacher Education International Education Conference Proceedings, 2016(1), 2702-2708. Paper presented at the SITE Annual Conference, Savannah, GA. Retrieved from http://www.editlib.org/j/SITE/

McLaughlin, J. E., Roth, M. T., Glat, D., Gharkholonarehe, N., Davidson, C., Griffin, L.,...Mumper, R. J. (2014). The flipped classroom: A course design to foster learning and engagement in health professions education. Academic Medicine, 89(2), 236-243.

Pashler, H., McDaniel, M., Rohrer, D., \& Bjork, R. (2009). Learning styles: Concepts and evidence. Psychological Science in the Public Interest, 9(3), 105-119. doi: 10.1111/j.1539-6053.2009.01038.x
Sipress, J. M., \& Voelker, D. J. (2008). From learning history to doing history: Beyond the coverage model. In R. A. Gurung, N. L. Chick, \& A. Haynie (Eds.), Exploring signature pedagogies: Approaches to teaching disciplinary habits of mind (pp. 19-35). Sterling, VA: Stylus.

Solomon, S. J. (2004). Can we discuss this? The passing of the lecture. The Midwest Quarterly: A Journal of Contemporary Thought, 46(1), 83-94. Retrieved from http://www.pittstate.edu/info/midwestq/ index.dot

Strayer, J. F. (2012). How learning in an inverted classroom influences cooperation, innovation, and task orientation. Learning Environments Research, 15, 171-193. doi: 10.1007/s10984012-9108-4

Stone, B. B. (2012). Flip your classroom to increase active learning and student engagement. Paper presented at the 28th Annual Conference on Distance Teaching and Learning, Madison, WI. Retrieved from

http://www.uwex.edu/disted/conference/ Resource_

library/proceedings/56511_2012.pdf

Tinto, V., \& Pusser, B. (2006). Moving from theory to action: Building a model of institutional action for student success. National Postsecondary Education Cooperative. Retrieved from https://nces.ed.gov/npec/

Toto, R., \& Nguyen, H. (2009). Flipping the work design in an industrial engineering course. Paper presented at the 39th ASEE/IEEE Frontiers in Education Conference, San Antonio, TX. doi: 10.1109/FIE.2009.5350529 
Willingham, D. T. (2009). Why don't students like school? A cognitive scientist answers questions about how the mind works and what it means for the classroom. San Francisco, CA: Jossey-Bass.

\section{Appendix A: Flipped Class Overview}

\section{Overview}

This appendix provides two specific examples of activities that took place in the flipped class face-to-face that occurred in the traditional class at home on their own in line with the standard approach to flipping the classroom. It is hoped that readers will use these illustrations to have a clearer sense of the distinctions in each setting.

\section{General Classroom Format}

\begin{tabular}{|l|l|l|}
\hline Time & Lecture-Based Class & Flipped Class \\
\hline 11:00 - 11:05 & Welcome, Day Overview, \& Review & Welcome, Day Overview, \& Review \\
\hline 11:05 - 11:15 & $\begin{array}{l}\text { Extended Review and Q\&A from } \\
\text { Readings }\end{array}$ & Sub-Groups Opening Activity \\
\hline $11: 15-11: 45$ & Lecture & Class Discussion \\
\hline $11: 45-12: 00$ & $\begin{array}{l}\text { Extension and/or Reinforcement } \\
\text { Activity }\end{array}$ & $\begin{array}{l}\text { Extension and/or Reinforcement } \\
\text { Activity }\end{array}$ \\
\hline 12:00 - 12:10 & Allocated as appropriate & Allocated as appropriate \\
\hline 12:10 - 12:15 & $\begin{array}{l}\text { Closure, Review, \& To Do } \\
\text { Discussion }\end{array}$ & $\begin{array}{l}\text { Closure, Review, \& To Do } \\
\text { Discussion }\end{array}$ \\
\hline
\end{tabular}

Inserted from Table 1 within text of the document

\section{Sample Flipped Activities}

Example \#1: Why some states celebrate Native American Day on Columbus Day?

Quick Synopsis: Students explored how states memorialize particular events based upon historical significance. In addition to a popular article illustrating this as a contemporary controversy, students were provided a set of primary source materials to read, discuss, and utilize in the development of a historical argument in support of their chosen name for the holiday.

a. Students in the traditional class received a packet of materials introduced in the extension/reinforcement activity time and were required to complete it on their own before the next session

b. Students in the flipped class spent the sub-groups opening activity reading the contemporary article as an 'entry event' to the controversy and the entire class discussion and extension time completing the task together in teams 
Example \#2: Perspectives on Federal-American Indian Relations

Quick Synopsis: Students were required to interact with definitions of civilization and sovereignty, with historical descriptions from varied perspectives on federal rulings and laws, several primary source excerpts related to boarding schools, and their knowledge from reading/lectures to distinguish between the perspectives and to take on a particular perspective.

a. Students in the traditional class took part in an instructor-led, subgroup discussion on the concepts of civilization and sovereignty and received instructions as to how to complete a subsequent packet exploring historical descriptions, primary source materials, and their textbook/notes to differentiate between diverse views on assimilation policies (during the extension and/or reinforcement activity time)

b. Students in the flipped class spent the sub-groups opening activity discussing definitions and concepts of civilization and sovereignty, the full class debriefed together, and then during class discussion time groups interacted with the provided readings drawing on aspects from their previous knowledge and with one another. Finally, during the extension/reinforcement time, teams took on the historical perspective of an assigned role (either assimilationist or non-assimilationist) and discussed from that vantage point and in alignment with resources from the provided materials various topics. Finally, the class completed a whole class debriefing in the last ten minutes of class.

Dr. Kevin S. Krahenbuhl is Assistant Professor of Education at Middle Tennessee State University. He has nearly a decade of K12 teaching experience and five years of work collaborating between university and K12 schools to promote enhanced teaching and learning. He is an advocate for effective integration of technology to leverage learning and presently works with doctoral students in the Assessment, Learning, and School Improvement Ed.D. program at MTSU. His research interests include learning and assessment of historical understanding, technology integration for enhanced learning, and educational improvement. 